\title{
IDIOPATHIC CHRONIC HEMATOCELE OF THE VAGINAL SAC
}

\author{
CARLOS ALVAREZ-ALVAREZ, LUIS A. FARINA-PEREZ, CELSO R. BARROS
}

Departments of Pathology (CAA), Urology (LAFP) and Radiology (CRB), Hospital POVISA, Vigo, Spain

\begin{abstract}
We report a 39-year-old male who presented non-traumatic testicular swelling and pain. Physical examination and sonography presented a suspicion of testicular tumor and both surgical exploration and inguinal orchiectomy were performed. Hematocele may both clinically and sonographically resemble a testicular tumor. The diagnostic study of choice is magnetic resonance, establishing the diagnosis and differentiating it from neoplasms.
\end{abstract}

Key words: testis; hematocele; magnetic resonance imaging

Int Braz J Urol. 2005; 31: 555-7

\section{INTRODUCTION}

Differential diagnosis of a scrotal mass includes inflammatory conditions, malignant tumors and traumatic lesions including hematomas. Acute hematocele is commonly associated with testicular trauma, but some cases may be idiopathic. The clinical presentation is that of a testicular tumor, and the main clinical significance lies in the difficulty encountered in excluding malignant lesions preoperatively (1). Correct management includes early recognition and treatment to preserve the testicle.

\section{CASE REPORT}

A 39-year-old man with a history of meningitis presented a 1-month history of testicular pain and scrotal swelling. The patient did not refer previous trauma in the area. Scrotal examination revealed an enlarging hard, nontender mass in the right side. Testicular tumor markers were within normal range. Ultrasonography showed an extra testicular mass with solid hyperechoic areas separated by irregular septations, suggesting an abscess or hematocele (Figure-1). Magnetic resonance imaging (MRI) revealed a well-defined encapsulated right solid mass of high signal intensity on T1-weighted images in the region of the epididymal body (Figure-2). During the surgical exploration, an encapsulated hematoma in the close vicinity of the testicle and epididymis was observed. As the lesion was severely attached to the spermatic cord, testicle could not be saved, and inguinal orchiectomy was performed. Gross examination of the resected specimen showed a cavity containing blood clots with a thick capsule that isolated the lesion from the surrounding normal structures (Figure-2). Histopathological examination showed abundant macrophages, hemosiderin, and dystrophic calcification, consistent with an organized hematoma. The diagnosis was idiopathic chronic hematocele.

\section{COMMENTS}

Hematocele results from the accumulation of blood within the vaginal sac and can reach large volumes. Most patients with hematocele have a previ- 


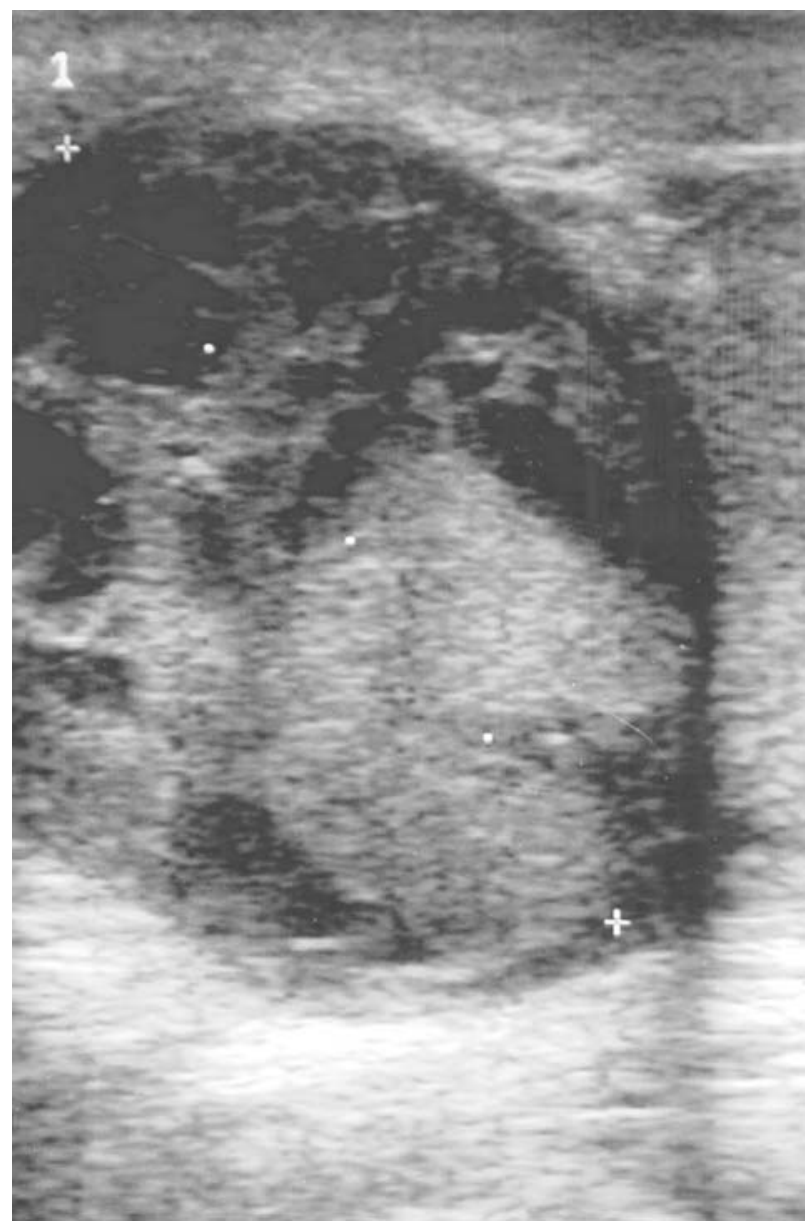

Figure 1 - Ultrasonography showing a well-defined extra testicular mass with cystic and solid areas.

ous history of testicular trauma, and are admitted to the hospital due to acute testicular pain (2).

According to an etiological basis, hematoceles can be classified as idiopathic and secondary, although most of the idiopathic are thought to be secondary to asymptomatic trauma or infection as well. Idiopathic or spontaneous bleeding seems to be more common in elderly patients (1), and hematoma is the result of blood leakage into the vaginalis sac. Non-traumatic secondary hematoceles can be produced by hematological alterations or vasculitis (3). The etiology of the hematocele formation in our patient is unknown.

Hematocele is difficult to diagnose preoperatively because its symptoms may mimic cysts or neoplasms. Testicle exploration shows a mass, and
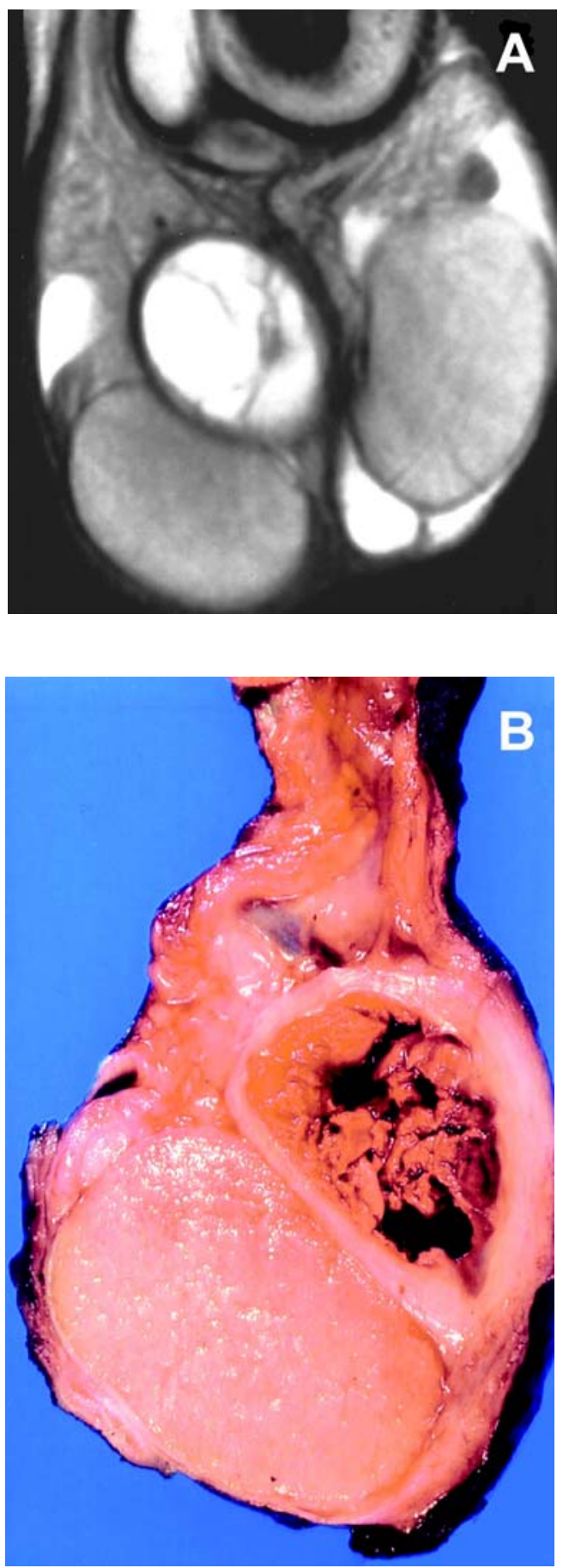

Figure 2 - A) MRI showing a hemorrhagic encapsulated lesion in the region of the epididymal body. B) Surgical specimen. Hematoma in the paratesticular area is pushing the testis toward the periphery. 
ultrasonography is very helpful for screening of hematocele, but presents some difficulties to its final diagnosis (2). MRI has a higher sensitivity, allows clear demonstration of blood, and can be regarded as mandatory for the diagnosis. Surgical exploration may be needed when the diagnosis is in question.

Conservative approach usually produces unsatisfactory results (2). Correct management includes early recognition and complete evacuation of the hematoma to avoid testicular compression (2), preventing epididymo-orchitis, abscess formation and necrosis, as unresorbed hematocele can eventually be infected.

\section{CONFLICT OF INTEREST}

None declared.

\section{REFERENCES}

1. Leibovitch I, Ramon J, Ben Chaim J, Nass D, Goldwasser B: Chronic hematocele complicating renal failure and hemodialysis. J Urol. 1991; 146: 162-4.

2. Altarac S: Management of 53 cases of testicular trauma. Eur Urol. 1994; 25: 119-23.

3. Pascual Regueiro D, Garcia de Jalon Martinez A, Trivez Boned MA, Sancho Serrano C, Gracia Montoliu S, Rioja Sanz LA: Idiopathic superinfected giant hematocele. Actas Urol Esp. 2003; 27: 645-8.

Received: April 15, 2005

Accepted after revision: June 20, 2005

\author{
Correspondence address: \\ Dr. Carlos Álvarez-Álvarez \\ Department of Pathology, Hospital POVISA \\ C/Salamanca 5, Vigo, 36211, Spain \\ Fax: + $3498642-1439$ \\ E-mail: capialvarez@yahoo.com
}

